ORIGINAL ARTICLE

\title{
Bringing psychosocial support to headache sufferers using information and communication technology: Lessons learned from asking potential users what they want
}

\author{
Anna Huguet $\mathrm{PhD}^{1,2}$, Jennifer Stinson $\mathrm{PhD}^{3}$, Bonnie MacKay $\mathrm{PhD}^{4}$, Carolyn Watters $\mathrm{PhD}^{4}$, \\ Michelle Tougas $\mathrm{BA}^{1}$, Meghan White $\mathrm{BA}^{3}$, Patrick J McGrath $\mathrm{PhD}^{1,2}$
}

\begin{abstract}
A Huguet, J Stinson, B MacKay, et al. Bringing psychosocial support to headache sufferers using information and communication technology: Lessons learned from asking potential users what they want. Pain Res Manag 2014;19(1):e1-e8.
\end{abstract}

BACKGROUND: Headaches are a major concern for which psychosocial interventions are recommended. However, headache sufferers do not always have ready access to these interventions. Technology has been used to improve access, especially in young people.

OBJECTIVES: To examine user preferences to inform the development of an Internet-based psychosocial intervention including smartphone technology, referred to as the Wireless Headache Intervention.

METHODS: The methodology followed a participatory design cycle, including 25 headache sufferers (14 to 28 years of age) who informed the prototype design. All participants were familiar with smartphones and the Internet. Through two iterative cycles of focus groups stratified according to age, qualitative data were collected by asking user preferences for the different planned components of the intervention (ie, smartphone pain diary, Internet-based self-management treatment, social support) and other relevant aspects (ie, smartphone versus computer delivery, and ways of reaching target audience). NVivo 8 with content analysis was used to analyze data and reflect themes as guided by the thematic survey.

RESULTS: Participants reported a preference for completing the smartphone pain diary on a daily basis. Participants believed that the program should facilitate easy access to information regarding headaches and management strategies. They also wanted access to other headache sufferers and experts. Participants believed that the program should be customizable and interactive. They reinforced the need and value of an integrated smartphone and Internet-based application.

CONCLUSIONS: The results provide insight into a participatory design to guide design decisions for the type of intervention for which success relies largely on self-motivation. The results also provide recommendations for design of similar interventions that may benefit from the integration of mobile applications to Internet-based interventions. The present research contributes to the theoretical frameworks that have been formulated for the development of Internet-based applications.

Key Words: Distance treatment; Focus group; Headache; Psychosocial intervention; Wireless

\section{Apporter un soutien psychosocial aux personnes souffrant de céphalées à l'aide de la technologie de l'information et de la communication : leçons apprises en demandant aux utilisateurs potentiels ce qu'ils veulent}

HISTORIQUE : Les interventions psychosociales sont recommandées en cas de céphalées, qui constituent une préoccupation importante. Cependant, les personnes qui souffrent de céphalées n'y ont pas toujours facilement accès. La technologie a déjà été utilisée pour améliorer cet accès, surtout chez les jeunes.

OBJECTIFS : Examiner les préférences des utilisateurs pour corroborer l'élaboration d'une intervention psychosociale virtuelle incluant une technologie de téléphone intelligent, la Wireless Headache Intervention.

MÉTHODOLOGIE : La méthodologie respectait un cycle participatif, et 25 personnes souffrant de céphalées (de 14 à 28 ans) ont rendu compte du prototype utilisé. Tous les participants connaissaient bien les téléphones intelligents et Internet. Au cours de deux cycles itératifs de groupes de travail stratifiés selon l'âge, les chercheurs ont colligé des données qualitatives sur les préférences des utilisateurs envers les divers volets prévus de l'intervention (journal de la douleur par téléphone intelligent, traitement virtuel autonome, soutien social) et d'autres aspects pertinents (transmission par téléphone intelligent ou par ordinateur pour atteindre le public cible). Les chercheurs ont fait appel au logiciel NVivo 8 et à l'analyse de contenu pour analyser les données et refléter les thèmes découlant d'un sondage thématique.

RÉSULTATS : Les participants ont déclaré préférer remplir le journal quotidien de la douleur sur leur téléphone intelligent. À leur avis, le programme devrait favoriser un accès facile à l'information sur les céphalées et les stratégies de prise en charge. Ils désiraient également avoir accès à d'autres personnes souffrant de céphalées et à des experts. Selon eux, le programme devrait être adaptable et interactif. Ils ont souligné la nécessité et l'importance d'une application intégrée pour téléphone intelligent et Internet.

CONCLUSIONS : Les résultats donnent un aperçu d'une méthodologie participative pour orienter la prise de décisions sur le type d'intervention dont le succès dépend largement de la motivation personnelle. Ils contiennent également des recommandations pour concevoir des interventions similaires susceptibles de profiter de l'intégration d'applications mobiles à des interventions virtuelles. Les présents travaux contribuent à la création des cadres théoriques formulés pour élaborer des applications virtuelles.

Internet holds promise for revolutionizing the way treatment of recurrent pain conditions is given and received (8-11). Internet-based treatments cost less and have the potential to reach large numbers of people in need of treatment. The first studies involving recurrent headache populations have found psychological Internet-based interventions to be effective in reducing headache frequency, duration and intensity $(9,11)$.

Information and communication technology (ICT)-based psychosocial therapies for pain conditions, including headaches, are most

\footnotetext{
Primary headache disorders are a major public health concern $(1,2)$. Over-the-counter drug treatment is usually the first and only treatment offered, and is not always sufficient to relieve or prevent headaches. The use of a multidisciplinary biopsychosocial approach, including psychological treatment, is recommended for effective management $(3,4)$. While existing psychological treatments have proven to be beneficial $(5,6)$, there are many headache sufferers who do not receive these benefits due to geographical, economic and educational barriers that limit the access to these treatments (7). The
}

${ }^{1}$ Centre for Pediatric Pain Research, IWK Health Centre; ${ }^{2}$ Departments of Psychology, Pediatrics and Psychiatry, Dalhousie University, Halifax,

Nova Scotia; ${ }^{3}$ Hospital for Sick Children, Toronto, Ontario; ${ }^{4}$ Faculty of Computer Science, Dalhousie University, Halifax, Nova Scotia

Correspondence: Dr Anna Huguet, IWK Health Centre, 5850/5980 University Avenue, Room K8508, PO Box 9700, Halifax, Nova Scotia

B3K 6R8. Telephone 902-470-7521, fax 902-470-6534, e-mail anna.huguet@iwk.nshealth.ca 
commonly provided on a desktop personal computer (PC) $(9,12)$. Mobile communication technology is becoming increasingly popular as a means of improving health care $(13,14)$ due to its advantageous features over the PC (ie, point of care access, portability, uninterrupted data stream and processing power to run multimedia software applications). For example, several headache smartphone applications have been developed, mostly for headache assessment through an electronic diary (15-17). However, mobile-based applications are limited by the amount of text and data visible on a screen and may not be able to support all features delivered on other Internet-based applications (eg, videos, interactive games). Apart from this, the current ICT-based applications, regardless of their mode of delivery, are often criticized for lack of involvement of health care professionals, poor evidence of integration of research findings or theories in application features, and inadequate testing (eg, randomized controlled trials) (14). Consequently, there is a need to improve the development, and assess the clinical benefits and outcomes of evidence-based psychosocial treatments for headache sufferers using integrated smartphone and Internet-based applications.

ICT-based interventions are anticipated to be readily accepted and adopted by adolescents and young adults who experience headaches because this population represents one of the most active and fastestgrowing group of users of this technology (eg, in 2011, 29.5\% of 12- to 17 -year-olds and $54.5 \%$ of 18 - to 24 -year-olds had smartphones; it is projected that $65.4 \%$ of 12 - to 17 -year-olds and $87.3 \%$ of 18 - to 24-year-olds will have smartphones in 2016) $(18,19)$.

When developing these applications, there is critical need to bridge the gap between designers/providers and users by incorporating user preferences with respect to essential features through a user-centred participatory design approach (20). Considering incorporation of user preferences when designing these programs is expected to increase use $(21,22)$. There are no up-to-date, conclusive results regarding features that should be incorporated into Internet-based interventions based on user preferences. Ritterband et al (23) developed a behavioural change model for the development of Internet-based interventions that highlights the website program (including the following areas: appearance, personalization, burdens, content, modes of delivery and participant engagement) as a major component that can influence intervention utilization and, in turn, predict and explain behaviour change, improve symptoms and maintain improvement. However, this model does not provide guidance about what characteristics for this critical component are necessary for the success of the intervention (24). Very few health care applications follow the user-centred design and fail to involve the user early in the development process to start determining which elements may provide the most robust treatment program for each of these areas (25).

Our overall goal is to develop an integrated smartphone and Internet-based psychosocial intervention for assessing and treating individuals with headache between 14 and 28 years of age because this age group is comprised of 'digital natives' $(26,27)$ and headaches often start and become more frequent in this age range (28). This program, referred to as the Wireless Headache Intervention (WHI), was conceptualized to include a smartphone-based diary system for motivating and empowering the user to make self-observations of headaches, monitoring progress and assessing achievements; opportunities for social support (via smartphone and/or PC); and an Internet-based headache self-management program without human coaching support for cost-effectiveness reasons. The purpose of the present article is to provide guidance for developing an Internet-based intervention based on the participatory design process. The results of the present qualitative study were used to develop a set of recommendations based on user preferences when designing this type of intervention, using the Ritterband et al (23) model of behaviour change through an Internet intervention as a theoretical framework. The present study, therefore, may benefit other researchers or designers with intentions of developing Internet-based health applications. They can learn from our experience and also mimic the same procedure that we have followed to inform the design of their application. In addition, the present study may help providers make informed choices about which health applications to recommend their patients.

\section{Procedure}

\section{METHODS}

Participants were divided into age groups (14 to 17 years, 18 to 21 years and 22 to 28 years) in an attempt to increase within-group homogeneity of participants and reduce communication inhibition in a group setting (29-31). Two iterative cycles of three focus groups (one from each age group) were conducted at the IWK Health Centre (Halifax, Nova Scotia). Participants were recruited through posters, brochures, online advertisements, letters and word of mouth. Participants expressed interest through e-mail to an address provided on the recruitment materials. A telephone call convenient for the participant was scheduled with a research assistant (MT). All potential participants were screened for study eligibility by the research assistant over the telephone on the basis of headache duration and frequency, age, and ownership of and familiarity with smartphones. Individuals who were informed and interested in participating were consecutively assigned to the focus group sessions. The focus group procedure was first pilot tested with five volunteers; no significant changes were considered for addition to the survey guide or focus group process after performing this pilot test. The data collected from this pilot study were not included in the analysis because it was designed to test the focus group methods rather than gather data from participant responses. The focus group sessions began by obtaining written consent from participants between 17 and 28 years of age. For adolescents 14 to 16 years of age, before obtaining written assent at the beginning of the focus group session, parental authorization was requested during the initial screening telephone call. Two moderators ( $\mathrm{AH}, \mathrm{BM})$ guided the focus group discussions using an open-ended standardized thematic survey guide (32) (Table 1). One group facilitator (MT) introduced the study, was responsible for audiotaping, and distributed the consent/assent forms and questionnaires. At the end of the session, participants completed a background information questionnaire about demographics, headache experience and smartphone use for descriptive purposes. Participants were reimbursed with a $\$ 30.00$ gift card. Each full session, including welcome and presentations, the consent/assent process, presentation of the WHI, the focus group interview and the administration of questionnaires, lasted approximately $1.5 \mathrm{~h}$ (range $1.25 \mathrm{~h}$ to $1.75 \mathrm{~h}$ ). Refreshments and snacks were provided throughout the sessions to promote participant comfort and reduce fatigue. The study protocol was approved by the institutional research ethics board.

In the focus group discussions, using the thematic survey guide, participants were asked to discuss what they wanted or would like to see in the WHI psychosocial headache intervention and to provide the rationale behind their suggestions. To help participants with the discussion on the design and possible features of the program regarding the main topics, scenario materials were provided using MockApp (www.mockapp.com), which provides PowerPoint (Microsoft Inc, USA) interface templates (Figure 1 presents options of mocked-up screenshots). For the purposes of evaluating the application, it was decided to design an iPhone (Apple Inc, USA) prototype because it is not trivial to simultaneously program multiple mobile operating systems. Consequently, when required, iPhone interface ideas were displayed. The iPhone application was chosen over other platforms because the iPhone is the platform with the strictest interface guidelines, and is popular with younger users - the target population - with the majority of iPhone users being $<35$ years of age $(25,33,34)$. In addition, the iPod Touch (Apple Inc, USA) provides an alternative to a mobile phone for receiving the iPhone-based intervention program, particularly for young users (eg, a recent survey identified that $69 \%$ of iPod Touch users are between 13 and 24 years of age [33]). In the future, this application will be developed for other mobile devices (eg, Android smartphones [Google Inc, USA] and tablets) and the 
TABLE 1

Ninety-minute focus group thematic survey guide

\begin{tabular}{|c|c|c|}
\hline Topic & Examples of questions & Time, min \\
\hline \multicolumn{2}{|c|}{$\begin{array}{l}\text { Presentation of the Wireless Headache Intervention idea, including brief description of its three components: diary, social support and } \\
\text { self-management program (as described in the introduction) }\end{array}$} & 10 \\
\hline Warm-up questions & Can you tell us what your headaches are like? What have you attempted in order to manage your headaches? & 5 \\
\hline Smartphone pain diary & $\begin{array}{l}\text { What would you like to keep track of? What would be the best way for entering this information into the diary? } \\
\text { What do you like and dislike about each of the different input types? What can we do to make the diary easier } \\
\text { and useful for you? }\end{array}$ & 15 \\
\hline $\begin{array}{l}\text { Internet-based self-management } \\
\text { treatment }\end{array}$ & $\begin{array}{l}\text { What do you think that the goals of this treatment should be? What would you like to learn? How you would like } \\
\text { to be taught? }\end{array}$ & 15 \\
\hline $\begin{array}{l}\text { Social support (via smartphone or } \\
\text { personal computer) }\end{array}$ & $\begin{array}{l}\text { What do you think about having some opportunities to talk with others? What other people would you like to } \\
\text { participate? What role you would like the people to take in this program? What social networking applications } \\
\text { do you use? Which features of these social networking applications do you like? Why? }\end{array}$ & 15 \\
\hline $\begin{array}{l}\text { iPhone (Apple Inc, USA) versus } \\
\text { computer delivery }\end{array}$ & $\begin{array}{l}\text { What do you think the advantages of designing a program that will use both the iPhone and the Internet for } \\
\text { your computer are? Do you think there are disadvantages? When do you feel that you would use the iPhone } \\
\text { and when the computer? }\end{array}$ & 15 \\
\hline Reaching target population & $\begin{array}{l}\text { How and where should we advertise or let people know that this program is available to young people with } \\
\text { headaches? What would make you hesitate in participating? }\end{array}$ & 10 \\
\hline Closing & Do you have any other additional comments, questions or suggestions? & 5 \\
\hline Total duration & & 90 \\
\hline
\end{tabular}

different platform specifications (eg, interface and interactions styles) will be taken into consideration (35). While this is a more costly approach, it would increase the number of users who could be reached using these types of interventions. In an attempt to avoid introducing bias during the focus group discussions, participants were asked openended questions about their preferences and suggestions for each of the topics before visuals were shown. Three focus groups for each age range in cycle 1 were conducted. The second cycle was built on the first, with modifications introduced to the survey guide to stimulate further specific discussion including more probing questions regarding the same topics with suggestions and examples to be discussed.

Focus group interviews were audiotaped and transcribed verbatim by a professional transcriptionist external to the research. All transcripts were imported into NVivo 8.0 (QSR International, Australia), a qualitative analysis software program that helps to organize, code and retrieve data. The analysis using NVivo was conducted by one member of the research team (MW). A 50\% sample of the data (the data collected from the first cycle of focus groups) was manually coded by two members of the research team (AH, MT) for comparison as a measure of reliability (confirmability) (36) and to ensure that analysis was consistent with study objectives. Disagreements (eg, wording of themes) were handled through consensus of three members of the research team (AH, JS, MW).

Simple content analysis was used for the analysis of qualitative data as outlined by Sandelowski (37). Using this method, all data were read several times to obtain an overall understanding of the data and develop codes. These codes were compared with the themes of the survey guide and used to generate categories. Overarching themes and relationships among the generated categories were determined using matrices. As data were entered into the analyses, categories were continuously generated until there were no new data that could be categorized under existing codes. Theoretical saturation was assumed to be reached when no further themes, categories or relationships could be identified $(38,39)$.

\section{Measures}

Sociodemographic information: Information regarding age, sex and highest level of education completed was collected at the end of the focus group.

Pain information: Headache intensity, duration, interference and headache diagnostic were assessed using self-report. An 11-point numerical rating scale was used to assess the headache intensity. Participants were asked to indicate a number from 0 ('no pain') to

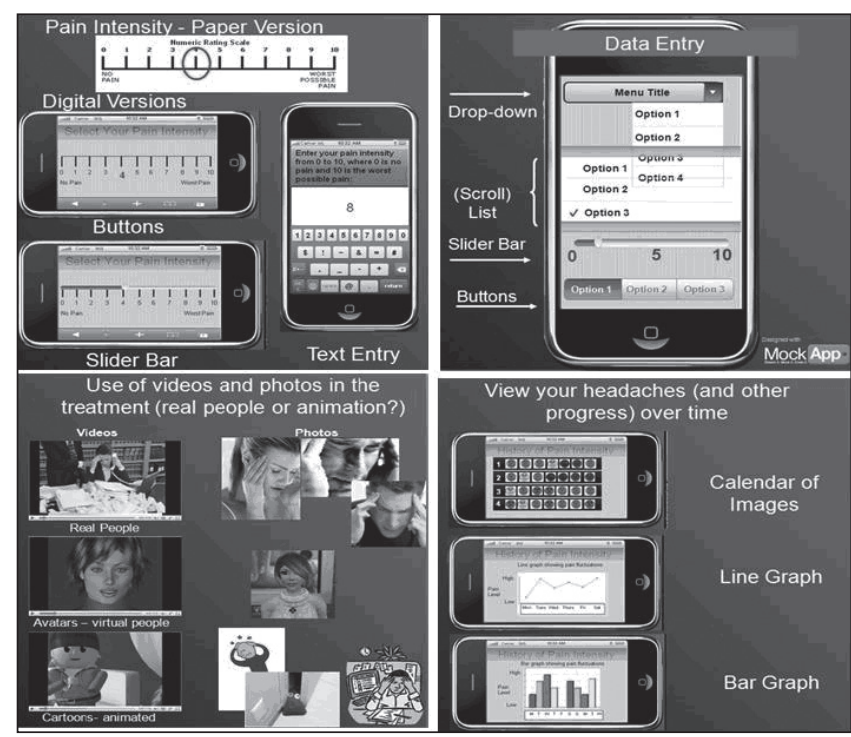

Figure 1) Examples of iPhone (Apple Inc, USA) interface templates that were used during the focus groups

10 ('worst pain') to express the highest and the most common intensity of their headaches over the past three months. This scale is widely recommended $(40,41)$ and has shown to be a valid measure of pain intensity in both children and adult populations $(42,43)$.

To measure the impact of headache on participant lives during the previous three-month period, the Migraine Disability Assessment (MIDAS) and the Pediatric Migraine Disability Assessment (PedMIDAS) were administered. The MIDAS questionnaire, developed to be used by adults, was administered to participants $\geq 20$ years of age. The MIDAS questionnaire assesses how much headache impacts on paid work, school, household work and nonwork time including family, social and leisure activities. The PedMIDAS questionnaire, which was developed for children and adolescents using MIDAS as a template, was administered to study participants 14 to 19 years of age (39). The PedMIDAS questionnaire assesses the impact of headache on school performance and participation in other activities. The reliability and validity of both forms has been previously explored in young adults and adolescents who experience headaches $(44,45)$. A validated grade system of MIDAS and PedMIDAS allows the 


\section{TABLE 2}

Descriptive information of the participants

\begin{tabular}{lc}
\hline Characteristic & $\begin{array}{c}\text { Total sample } \\
\text { (n=25) }\end{array}$ \\
\hline Sex & \\
Male & $6(24)$ \\
Female & $19(76)$ \\
Reported headache diagnosis & \\
$\quad$ Migraine & $5(20)$ \\
Tension-type headache & $11(44)$ \\
Both migraine and tension-type headache & $5(20)$ \\
Other & $2(8)$ \\
I do not know & $3(12)$ \\
Headache characteristics & \\
Highest intensity over the past three months, mean \pm SD & $7.40 \pm 1.71$ \\
Most common intensity over the past three months, & $4.76 \pm 1.69$ \\
$\quad$ mean \pm SD & \\
Duration, median (range) & 7.5 years \\
& $(8$ months to \\
& 19 years) \\
Disability (MIDAS/PedMIDAS) & \\
Little or no disability & $3(12)$ \\
Mild disability & $8(32)$ \\
Moderate disability & $7(28)$ \\
Severe disability & $7(28)$ \\
\hline
\end{tabular}

Data presented as $n(\%)$ unless otherwise indicated. *Information from three participants was missing. MIDAS Migraine Disability Assessment; PedMIDAS Pediatric MIDAS

classification of the respondents into one of four grades of disability (ie, little or no disability, mild, moderate and severe disability) $(46,47)$.

Technical information: Participants were asked whether they had a cell phone or smartphone, what type and about their usage of the devices.

\section{Study participants}

A reduced number of participants per session (a minimum of four participants and a maximum of seven) was planned to facilitate recruitment, conduct the planned sessions and analyze data. This group size is consistent with recommendations in the literature $(48,49)$. Inclusion criteria for participation in these sessions were: age between 14 and 28 years; experiencing recurrent headaches for at least three months, occurring with a minimum frequency of two per month as reported by the individual; and for individuals between the ages of 17 and 28 years, own a smartphone or, for individuals between 14 and 16 years of age, have used a smartphone, either their own smartphone or someone else's, without the need to own one because at these ages individuals may not be permitted by their parents or financially capable to own smartphones.

\section{Study participants}

Sixty-four individuals were approached. A total of 25 individuals (six male and 19 female) participated in focus group sessions. Thirty-nine individuals did not participate because they had scheduling conflicts with the sessions $(n=11)$, did not respond to the telephone screening call $(n=6)$, were ineligible $(n=3)$ or did not show up to scheduled focus group sessions $(n=19)$. For the first cycle of focus groups, three, three and five individuals participated in the youngest (14 to 17 years of age), middle (18 to 21 years of age) and oldest ( 22 to 28 years of age) age groups, respectively. In the second cycle, three, four and seven individuals participated in the youngest, middle and oldest groups, respectively. The majority (88\%) owned a smartphone. The most common types of smartphones owned were BlackBerry (BlackBerry
Limited, Canada) (57\%) followed by iPhone (36\%). Additional participant characteristics are presented in Table 2.

\section{Themes}

The five main themes of the focus groups analysis were headache experience, diary, treatment program, multidevice delivery and recruitment. Headache experience refers to the participant's experience with headaches including headache characteristics, level of interference, triggers and management. The diary theme categorizes the features of the diary that participants found appealing, including methods of diary entry, things participants believed the diary should capture and diary characteristics (personalization, interactivity, etc). Under the treatment program theme, participants described the aspects of the treatment they desired: general headache information, management strategies, medication information and social support. The final main theme, recruitment, describes the methods participants believed were best to use to recruit future participants. Each theme is further described below. Because the age division of the focus groups allowed for cross-group comparison and some differences were noted, these identified differences are elaborated on within each theme.

Headache experience: Participants reported experiencing headaches anywhere from once per month to daily, most often experiencing headache at least two to three times per week. Some participants were also able to describe the recurrent location of their headaches (ie, back of the neck, behind the eyes, always on left side) and classify their headache as either migraine or tension headaches. Participants described their headaches as disruptive, with participants indicating their headaches interfered with their school, work, social and daily activities:

School was really tough. High school, I actually had to drop a few courses just because I was missing so much time. And we're talking like three or four days a week on average. So there was no way that I could keep up academically. At the time I couldn't do very much at all (for over three years) - 18 to 21 years group, cycle 2 .

It mostly happens at school. And when I have to leave school, it's really disruptive because I leave once every two weeks for a half a day -14 to 17 years group, cycle 2 .

The most common method of management reported across all of the focus groups was over-the-counter medication (acetaminophen, ibuprofen), followed by resting activities (ie, lying down and sitting) and distraction (ie, watching television, trying to ignore headaches). Based on the cross-group comparisons, differences appeared to exist in favoured pain coping strategies. While the youngest group (14 to 17 years of age) indicated that they sleep, relax, do nothing and do not use medication during a headache, the older two groups rarely mentioned those strategies and instead indicated that they manage their headaches with distraction strategies, massage and exercise.

Diary: Participants strongly stated that it would be useful to for them to keep a diary:

Yes, it would definitely help because right at the time, you'll know what you're doing, where you're at, what's going on. Whereas when you get home, you may forget -22 to 28 years group, cycle 2 .

You could pick out like a lot of the triggers that would start your headaches -14 to 17 years group, cycle 2 .

Participants commented on the aspects of headache they believed the diary should capture, the methods of data input for diary, the frequency of diary entry and, finally, the desired diary features. There were three common topics that arose when participants discussed the type of things they want to enter into a headache diary. Participants believed that the diary should capture headache characteristics including intensity, duration, frequency, localization and timing of headaches (ie, starting and ending time); factors that may trigger or aggravate headaches through keeping track of daily activities, diet, sleep 
hygiene, stress level, time of day and environmental characteristics such as daily weather; and pain coping strategies, specifically recording medication intake, its level of effectiveness and strategies they use once a headache starts:

I think maybe that would help in terms of finding out what things trigger it, if there's any pattern in when my headaches come. Because I don't write anything down now, but maybe there's a pattern or something I'm doing that's triggering them -22 to 28 years group, cycle 1 .

I think it would be kind of useful for especially like dietary things. So if I was made more aware of that then maybe I'd avoid those foods -18 to 21 years group, cycle 2 .

When discussing methods of diary entry, the most common methods that were discussed were the drop-down list, scrolling, slider bar, buttons and text entry. Participants were also asked about using video, pictures and audio as modes of input. When appropriate, participants were shown digital examples of paper instruments commonly used by physicians to gauge patients' headaches, to help the flow of discussion (Figure 1). Across all groups, slider bars were indicated to be desirable, although one younger participant noted that he finds slider bars hard to move on the iPhone. Differences among age groups were also identified when reviewing discussions, especially when considering forms of data input other than text entry. The discussions with the youngest and the middle age groups favoured input methods through pictures, video and audio data. This was not the case for the oldest group, in which discussions focused on the primary form of input through text, which was considered to be less ambiguous by this group. Although the forms of data input of pictures, audio and video were favourably discussed by younger groups, they also mentioned potential problems:

If you're like in public and you have to record yourself or like a video call, it would be a little weird; if you're in school, you'd probably get in trouble for that -14 to 17 years group, cycle 1 .

When the frequency of completing the diary was discussed, participants believed that the diary should be used daily for a set time, whether headache was present or not, as long as it did not take too long and was easy to complete. Participants also wanted to have control over when to enter data in the diary during the day and believed it was important that they could stop and restart data entry at a later time at the point they left off.

Participants also talked about features that would make the diary more desirable to use such as profile creation, feedback in the form of progress tracking using graphics and diary entry reminders. Participants would like to visualize their progress through graphics by having feedback provided by displayed images (Figure 1) and have the option to choose what construct they want to see progress on as well as the type of graph to use. For diary entry reminders, the use of text messages and onscreen icons were the most commonly preferred form of reminder across all age groups. Comparing among groups based on the content of discussions, age-related differences may exist. The older participants (22- to 28-year-olds) mentioned that e-mail would be an acceptable reminder, whereas the 14 - to 17 -year-olds and 18- to 21 -year-olds did not favourably discuss e-mail; rather, both groups agreed that an audible alarm would also work. Participants suggested that the possibility of being able to control the type of reminders was appealing to them. Also, they believed that it was important to allow the reminders to be set to a customizable schedule so as not to interrupt daily activities (ie, meetings, exams, etc).

Treatment program: Reported personal end goals for participation in the WHI program predominantly centred on having a better understanding about their own headaches (eg, what triggers their headaches); having a better understanding on how to deal with and prevent headache; and reducing their headache frequency:
Pain and feeling better, so my quality of life is probably better, and if I have them less then I am able to study, which gets better grades, which gets better moods. So I feel like it all just ties into the main goal -18 to 21 years group, cycle 2 .

In this treatment program theme, participants outlined three main components they believed should make up the treatment program: headache information, management strategies and social support. Participants unanimously believed that the program should provide an abundance of general headache information including types of headache and their characteristics, common headache triggers and current headache research.

Participants also believed the program should include management strategies. Primarily, participants expressed an interest in medication information (eg, efficacy of each drug, side effects and drug incompatibilities). However, they also believed the program should discuss management strategies other than taking medication. Some participants were unaware of what is currently available and had difficulty providing suggestions for what the treatment should include; they wanted to learn things that may be useful but they did not know what those could be. Others suggested the inclusion of distraction strategies, relaxation strategies, homeopathic treatment information and lifestyle information (such as suggestions regarding how to eat well on a budget when poor diet is found to be a headache trigger). Participants indicated that they wanted to receive novel information and expert input from the program.

One feature that was discussed was related to graphic design when presenting the treatment. Participants, especially those in the older groups, most commonly preferred images of actual people as opposed to animated avatars because they produce more realistic messages.

Social support was the final component of the treatment program that participants discussed. Participants overwhelmingly indicated that they would like to receive advice from professional headache experts as well as wanting to talk with other headache sufferers. However, based on the content of the discussions, differences were found across age groups with regard to what format would be the best way to facilitate social support. The discussions of the younger group (14 to 17 years of age) strongly focused on preference of a chat or feature similar to Facebook, whereas discussions from the older group (22 to 28 years of age) centred around preference of a blog format. A more equal distribution of preference across all three age groups was observed in potentially using a discussion forum to communicate social support. Participants believed that, ideally, the forum would be moderated by a health care professional. Participants believed that the social support would help them to feel understood:

For me personally, like a lot of people in my school don't understand like the intensity of the headache I have. They just think of it as a regular headache. So I think it would be nice to talk to people who have the same and see what they do maybe, to share ideas -18 to 20 years group, cycle 1 .

If you're suffering a headache, others might come on and give you suggestions -14 to 17 years group, cycle 1 .

They also believed that the social support would help to share ideas, to see what others do, and receive tips and information about headache. However, concerns were raised, such as: they would not know how reliable the information derived from other participants would be; they could receive information that they already know; they may not receive any answers to their questions; they would not like to always hear others complain about their headaches; they may get bored with this feature; they may not have the time to dedicate to it; they may be afraid to join the social networking site because of privacy concerns; or they would not like to chat with 'random people'.

Multidevice delivery: Participants believed that program delivery over both iPhone and PC was ideal as long as the two devices were synchronized. They stated that this would provide them with the 


\section{TABLE 3}

\section{Focus group recommendations for developing an integrated smartphone and Internet-based intervention}

\begin{tabular}{|c|c|}
\hline Main areas* & Recommendations \\
\hline Appearance (look and feel of the application) & $\begin{array}{l}\text { - Provision of the opportunity to access large amount of text from big screens (desktop personal computer) and } \\
\text { short amounts of text from small screens (smartphone) }\end{array}$ \\
\hline
\end{tabular}

what to do to address the targeted problem)

Burdens (burdens of using the program)

Content (the actual treatment information)

Delivery (ways in which the content can be delivered)

Message (source and style of the content)

Participation (program's ability to engage and involve the user in the treatment)
- Use of easy diary input methods: slider bars, text (oldest age group), pictures (youngest and middle age group), video (youngest and middle age group), audio (youngest and middle age group)

- Short and flexible daily diary entries

- Short and simple description of the intervention in recruitment materials

- Provision of social support (peer and health care experts [in the case of a headache intervention, provision of others suffering headaches and headache experts])

- Provision of information on the health condition (in the case of a headache intervention, provision of information on headaches including types of headaches and their characteristics, headache triggers and current research)

- Provision of information on management strategies including medication (eg, drug efficacy, side effects, and incompatibilities) and effective strategies other than medication

- In the case of a headache intervention, diary collection of information on: headache intensity, duration, frequency, localization, timing of headaches, headache triggers, pain coping strategies, and medication intake and its effectiveness

- Inclusion of intervention length and contact information in recruitment materials

- Inclusion of real pictures in the treatment content

- Use of graphics to provide feedback on progress through the diary

- Use of text message or onscreen icons, email (oldest age group), and audible alarm (youngest and middle age groups) for daily diary remainders

- Use of chat or Facebook features (youngest group), blog (oldest group), and forum as a mode of support

- Synchronization between delivery devices (ie, smartphone and computer)

- Novel and expert input for the treatment content

- Provision of credible social support

- Use of a health care professional to actively and effectively moderate social interactions (eg, by providing reliable answers to users' questions, reinforcing appropriate communication and engaging users)

- Minimum risk of violation of privacy

- Use of credible advertisements through health care services, schools or universities, word-of-mouth by friends or family as a recruitment method

- Ability to create a profile

- Provision of feedback from the diary on progress over time (on the case of a headache intervention, progress on headache improvement)

- Ability to choose what diary feedback to receive

- Ability to choose what type of reminder and timing for the diary

- Ability for the users to decide level of involvement with the social network

*Areas that form the basis of Internet-based interventions according to Ritterband et al (23)

option to choose to complete small, quick tasks on the iPhone and larger amounts of text input and reading on the PC.

Recruitment: Participants suggested a variety of potential recruitment methods, with all three groups recommending use of posters and online advertisements. Other, more specific suggestions made were the use of cell phone carriers, social networking sites (eg, Facebook), online classifieds (eg, Kijiji), newspaper, physician referrals and schools. While participants indicated that the program would gain credibility if it was advertised through schools, recommendation by family or friends, or a health care service (eg, through physicians referrals or posters at the doctor's office), participants expressed some credibility concerns regarding advertisements through Facebook.

I think if a physician kind of presented me with, you know, try this, it would track your headache to see if we can find what is causing it and stuff like that, I would probably be really, really likely to do it. If it was just kind of an advertisement on Facebook, maybe not so much - 18 to 21 years group, cycle 1 .

I think doctors or like, some of my family or friends that talked about it. I don't think I agree with it being on Facebook or something because sometimes you don't know if those are real, or like, actually going to help - 18 to 21 years group, cycle 1 .

Participants would like to see a very short simple description of the program indicating the time required to follow the program as well as the degree of confidentiality involved. They would also like to see contact information to be able to find out more information.

\section{Summary}

Table 3 shows recommendations on how the application program should be developed and its functions, taking into consideration user perspectives and using the Ritterband et al (23) model as a framework.

\section{DISCUSSION}

The present study gathered potential end-user perspectives at the early developmental stage of an evidenced-based integrated smartphone and Internet-based psychosocial treatment program for adolescent and young adult headache sufferers, referred to as the WHI. Considering the lack of available information to guide development of Internetbased interventions and the often low actual use of Internet-based interventions (50), brainstorming of initial design ideas with potential end users was necessary to determine usable and desirable features for the WHI. The focus group participants supported the notion that integration of smartphone and Internet-based technology may increase intervention utilization and also provided suggestions for all of the main areas that are encompassed in the 'website program' component that influences intervention use according to Ritterband et al's model (23). We recommend that software designers, practitioners offering similar interventions and other researchers designing systems to deliver care consider these recommendations when developing or 
recommending ICT-based psychosocial interventions for young people suffering recurrent conditions, especially headaches.

The present study revealed the interest of participants having high levels of personalization and customization in the system design through many choices and options to improve effectiveness and meet unique developmental and personal needs. For instance, participants want the ability to decide content and format of diary reports, flexibility for entering information in the diary, the ability to create personalized profiles, the ability to set notifications for specific activities (eg, medication reminder) and the ability to choose type and time of reminders.

The use of tailoring in behavioural interventions based on likes/ dislikes is growing and is perceived to be appealing (51). However, researchers, providers and developers need to find ways to balance desired design features in these integrated applications with time, cost and evidence-based effectiveness. For instance, while several studies have shown that more interactive features increase usage and efficacy of the intervention $(52,53)$, few dismantling studies have been conducted to determine which features are most effective for whom. Rather than leaving this decision to the research team, end users could help with this process by rating importance of features. Researchers could then implement preference-based techniques that balance user preferences with costs.

Social support formats including message boards, chat rooms, mailing lists and instant messaging have been implemented and evaluated in health care fields other than headache, with high user satisfaction (54). Our participants considered the social component to be appealing, anticipating positive effects. A wide range of support features were endorsed, with opinions differing among participants.

A discussion forum format was positively endorsed by all participants, especially if moderated by a health care professional. Adding human support via brief telephone/e-mail contact with a therapist (eg, "Ask an Expert") has improved motivation and adherence to e-health care services, thereby optimizing achievement of desired outcomes $(55,56)$. Participants also expressed possible future worries, similar to the potential risks and barriers reported with existing online social networking $(57,58)$. One of the main concerns articulated by potential users was the risk of privacy issues. To minimize these concerns, researchers should host their site on secure servers, use data encryption, and make the site accessible to authorized members only through nontransferable passwords. Terms of use and guidelines for the site should also be created and clearly understood by participants while being enforced by a system administrator. For example, users should be advised not to post their name, geographical location or any other identifying information. Appropriate personnel to monitor discussions and intervene should be considered, if affordable, to reduce other concerns raised by users (eg, receive incorrect information from other peers, not receive an answer) (59).

The present study is not exempt from limitations. First, although the iPhone was chosen as the platform for the first prototype of the application, ownership was not required. Participants 17 to 28 years of age were required to own any type of smartphone, while participants 14 to 16 years of age were not required to own one, but to have experience using one. The comments of participants who did not own an iPhone could be influenced by lack of daily interaction with one. However, considering their input will be valuable when programming the WHI for other platforms. Second, it was not our initial intention to provide focus group participants with multiple choice or menus of items, but this became necessary when participants could not come up with their own unfettered ideas. Third, 'group-think' may have occurred in several of the groups. Instead of eliciting a range of perspectives, some groups exhibited a $100 \%$ or $0 \%$ consensus on some issues. Conducting individual interviews along with focus group interviews would have been appropriate to explore whether group-think affected the results. Fourth, some of the group sessions included only three participants, which is less than the minimum planned group size that is recommended $(48,49)$, due to a considerable proportion of participants failing to attend their scheduled session. This may have had negatively impacted the findings by producing fewer ideas than what could have been expected to be produced by a larger group size (60). Fifth, although it was not our intention to explore age-related differences when designing this study, due to the division of ages by focus group for the purposes of increasing group homogeneity and enhancing communication, we noticed age-related differences and, therefore, we performed tentative cross-group comparisons for age groups and reported the most relevant findings. One should not extrapolate these findings to a larger population but can use these to generate age-related hypotheses for field testing. Finally, most potential user preferences reported are not intervention specific. However, more research is needed to explore whether these preferences are equally applicable to those of users for other ICT-based interventions as well as representative of all headache sufferers. Focus groups, which have long been used in market research (61) and increasingly in medical research (62), are helpful for generating ideas and gaining input and feedback for designing an interface based on user needs and preferences $(63,64)$. Focus group discussion, however, may capture what people say they would like to see or do, and not necessarily what they actually will do and are not necessarily generalizable to the public.

\section{CONCLUSIONS}

The present study illustrates an approach that should be taken when developing an application to enhance its overall appeal and functionality before costly development is started. A user-centred participatory design approach from the very beginning of a project should be used to inform the development of an ICT-based psychosocial intervention. The present study extends Ritterband et al's (23) recent behavioural change model for Internet interventions to consider the smartphone technology as a mode of delivery intervention and user preferences when developing an ICT-based psychosocial intervention, and recommends future avenues of research regarding these areas.

ACKNOWLEDGEMENTS: The authors thank Drs C MacLean and J Miró for their input.

DECLARATIONS: The authors have no conflict of interest to declare. This research is funded by the Canadian Institutes of Health Research (grant \#97981). Dr Huguet was supported by a Postdoctoral Fellowship, Nova Scotia Health Research Foundation. Dr McGrath's research is supported by a Canada Research Chair.

\section{REFERENCES}

1. Lipton RB, Stewart WF, Diamond S, et al. Prevalence and burden of migraine in the United States: Data from the American Migraine Study II. Headache 2001;41:646-57.

2. World Health Organization. Mental Health: New understanding, new hope. The World Health Report, Geneva; 2001.

3. Seshia SS, Phillips DF, von Baeyer CL. Childhood chronic daily headache: A biopsychosocial perspective. Dev Med Child Neurol 2008;50:541-5.

4. Andrasik F, Flor H, Turk DC. An expanded view of psychological aspects in head pain: The biopsychosocial model. Neurol Sci 2005;25:S87-91.

5. Palermo TM, Eccleston C, Lewandowski AS, et al. Randomized controlled trials of psychological therapies for management of chronic pain in children and adolescents: An updated meta-analytic review. Pain 2010;148:387-97.

6. Trautmann E, Lackschewitz H, Kröner-Herwig B. Psychological treatment of recurrent headache in children and adolescents a meta-analysis. Cephalalgia 2006;26:1411-26.

7. Peng P, Stinson JN, Choiniere M, et al. STOPPAIN Investigators Group. Dedicated multidisciplinary pain management centres for children in Canada: The current status. Can J Anaesth 2007;54:985-91.

8. Bender JL, Radhakrishnan A, Diorio C, et al. Can pain be managed through the Internet? A systematic review of randomized controlled trials. Pain 2011;152:1740-50. 
9. Trautmann E, Kröner-Herwig B. A randomized controlled trial of Internet-based self-help training for recurrent headache in childhood and adolescence. Behav Res Ther 2010;48:28-37.

10. Hicks CL, von Baeyer CL, McGrath PJ. Online psychological treatment for pediatric recurrent pain: A randomized evaluation. J Pediatr Psychol 2006;31:724-36.

11. Devineni T, Blanchard EB. A randomized controlled trial of an Internet-based treatment for chronic headache. Behav Res Ther 2005;43:277-92.

12. Bromberg J, Wood ME, Black RA, et al. A randomized trial of a web-based intervention to improve migraine self-management and coping. Headache 2012;52:244-61.

13. Boulos MN, Wheeler S, Tavares C, et al. How smartphones are changing the face of mobile and participatory healthcare: An overview, with example from eCAALYX. Biomed Eng Online 2011;10:24.

14. Rosser BA, Eccleston C. Smartphone applications for pain management. J Telemed Telecare 2011;17:308-12.

15. BetterQOL. iHeadache. <http://www.betterqol.com/iheadache/ landing-nhf.html> (Accessed January 3, 2013).

16. Liu C, Holroyd KA, Zhu Q, et al. Design and implementation of a behavioral migraine management iPhone app for adolescents with migraine. IEEE International Symposium on World of Wireless Mobile and Multimedia Networks (WoWMoM) 2010:1-6.

17. Sorbi MJ, Mak SB, Houtveen JH, et al. Mobile Web-based monitoring and coaching: Feasibility in chronic migraine. J Med Internet Res 2007;9:e38.

18. Lenhart A. Teens, smartphones \& texting. Pew Internet 2012:1-4. $<$ http://www.pewinternet.org/Reports/2012/Teens-and-smartphones. aspx $>$ (Accessed July 2, 2013).

19. Smith A. 35\% of American adults own a smartphone. Pew Research Center Study; 2011. <http://pewinternet.org/ Reports/2011/Smartphones/Summary.aspx> (Accessed July 2, 2013).

20. Skeels MM, Pratt W. Participatory design with health consumers. AMIA Annu Symp Proc 2008;6:1136.

21. Glasgow RE, Klesges LM, Dzewaltowski DA, Bull SS, Estabrooks P. The future of health behavior change research: What is needed to improve translation of research into health promotion practice? Ann Behav Med 2004;27:3-12.

22. Johnson CM, Johnson TR, Zhang J. A user-centered framework for redesigning health care interfaces. J Biomed Inform 2005;38:75-87.

23. Ritterband LM, Thorndike FP, Cox DJ, et al. A behavior change model for internet interventions. Ann Behav Med 2009;38:18-27.

24. Riley WT, Rivera DE, Atienza AA, et al. Health behavior models in the age of mobile interventions: Are our theories up to the task? Transl Behav Med 2011;1:53-71.

25. Majid RA, Noor NL, Adnan WA, et al. A survey on user involvement in software Development Life Cycle from practitioner's perspectives. 5th International Conference on Computer Sciences and Convergence Information Technology (ICCIT) 2010:240-3.

26. Boneva BS, Quinn A, Kraut RE, Kiesler S, Shklovski I. Teenage communication in the instant messaging era. In: Kraut R, Brynin M, Kiesler S, eds. Computers, Phones, and the Internet: Domesticating Information Technology. New York: Oxford University Press, 2006:201-18.

27. Gross EF, Juvonen J, Gable SE. Internet use and well-being in adolescence. J Soc Issues 2002;58:75-90.

28. Steiner TJ, Scher AI, Stewart WF, et al. The prevalence and disability burden of adult migraine in England and their relationships to age, gender and ethnicity. Cephalalgia 2003;23:519-27.

29. Barbour R. Doing Focus Groups. London: Sage Publications, 2008:57-60.

30. Litosseliti L. Using Focus Groups in Research. London; New York: Continuum, 2003:28-40.

31. Bloor M, Frankland J, Thomas M, Robson K. Focus groups in social research. London; California: Sage Publications, 2001:20-5.

32. Sandelowski M, Barroso J. Classifying the findings in qualitative studies. Qual Health Res 2003;13:905-23.

33. MacTech Network. <http://www.mactech.com/content/study-looksdemographics-iphone-ipod-touch-users $>$ (Accessed on July 2, 2013).

34. Readwrite. <http://readwrite.com/2012/10/08/sorry-samsung-iphoneis-not-your-mothers-smartphone \#awesm $=\sim$ oary W2ujCJE20p $>$ (Accessed July 2, 2013).

35. Charland A, Leroux B. Mobile application development: Web vs. native. Commun ACM 2001;5:49-53.
36. Bradley J. Methodological issues and practices in qualitative research. Libr Q 1993;63:431-49.

37. Sandelowski M. Whatever happened to qualitative description? Res Nurs Health 2000;23:334-40.

38. Morgan DL. Focus Groups as Qualitative Research, 2nd edn. California: Sage Publications, 1997.

39. Creswell JW. Qualitative Inquiry and Research Design. California: Sage Publications, 1998.

40. McGrath PJ, Walco GA, Turk DC, et al. PedIMMPACT. Core outcome domains and measures for pediatric acute and chronic/ recurrent pain clinical trials: PedIMMPACT recommendations. J Pain 2008;9:771-83.

41. Dworkin RH, Turk DC, Farrar JT, et al. Core outcome measures for chronic pain clinical trials: IMMPACT recommendations. Pain 2005;113:9-19.

42. von Baeyer CL, Spagrud LJ, McCormick JC, et al. Three new datasets supporting use of the Numerical Rating Scale (NRS-11) for children's self-reports of pain intensity. Pain 2009;143:223-7.

43. Jensen MP, Karoly P, Braver S. The measurement of clinical pain intensity: A comparison of six methods. Pain 1986;27:117-26.

44. Hershey AD, Powers SW, Vockell ALB, et al. PedMIDAS: Development of a questionnaire to assess disability of migraines in children. Neurology 2001;57:2034-9.

45. Stewart WF, Lipton RB, Kolodne K, et al. Reliability of the Migraine Disability Assessment (MIDAS) score in a populationbased sample of headache sufferers. Cephalalgia 1999;19:107-14.

46. Hershey AD, Powers SW, Vockell AL, et al. Development of a patientbased grading scale for PedMIDAS. Cephalalgia 2004;24:844-9.

47. Lipton RB, Stewart WF, Sawyer J, et al. Clinical utility of an instrument assessing migraine disability: The Migraine Disability Assessment (MIDAS) questionnaire. Headache 2001;41:854-61.

48. Krueger R. Focus Groups: A Practical Guide for Applied Research, 2nd edn. California: Sage Publications, 1994:88-9.

49. Fem E. The use of focus groups for idea generations: The effects of group size, acquaintanceship, and moderator on response quantity and quality. J Market Res 1982;19:1-13.

50. Bennett GG, Glasgow RE. The delivery of public health interventions via the Internet: Actualizing their potential. Annu Rev Public Health 2009;30:273-92.

51. Womble LG, Wadden TA, McGuckin BG, et al. A randomized controlled trial of a commercial Internet weight loss program. Obes Res 2004;12:1011-8.

52. Patten CA, Rock E, Meis TM, et al. Frequency and type of use of a home-based Internet intervention for adolescents smoking cessation. J Adolesc Health 2007;41:437-43.

53. Williamson DA, Walden HM, White MA, et al. Two-year Internetbased randomized controlled trial for weight loss in AfricanAmerican girls. Obesity (Silver Spring) 2006;4:1231-43.

54. Griffiths KM, Calear AL, Banfield M. A Systematic review on Internet Support Groups (ISGs) and depression (1): Do ISGs reduce depressive symptoms? J Med Internet Res 2009;11:e40.

55. Barak A, Klien B, Proudfoot JG. Defining Internet-supported therapeutic interventions. Ann Behav Med 2009;28:4-17.

56. Ngugen HQ, Carrieri-Kohlman V, Ranki SH, et al. Internet-based patient education and support interventions: A review of evaluation studies and directions for future research. Comput Biol Med 2004;34:95-112.

57. White M, Dorman S. Receiving social support online: Implications for health education. Health Educ Res 2001;16:693-707.

58. Dumaij AC, Tissen EC. Online health companion contact among chronically ill in the Netherlands. Health Technol (Berl) 2011;1:5-23.

59. Henderson EM, Law EF, Palermo TM, et al. Case study: Ethical guidance for pediatric e-health research using examples from pain research with adolescents. J Pediatr Psychol 2012;37:1116-26.

60. Bouchard TJ Jr, Hare M. Size, performance, and potential in brainstorming groups. J Appl Psychol 1970;54:51-5.

61. Morgan DL. Focus Groups as Qualitative Research. California: Sage Publications, 1988.

62. Cohen DJ, Crabtree BF. Evaluative criteria for qualitative research in health care: Controversies and recommendations. Ann Fam Med 2008;6:331-9.

63. Stone D, Jarrett C, Woodroofe M, et al. User Interface Design and Evaluation. California: Morgan Kaufmann, 2005.

64. Sim J. Collecting and analysing qualitative data: Issues raised by the focus group. J Adv Nurs 1998;28:345-52. 


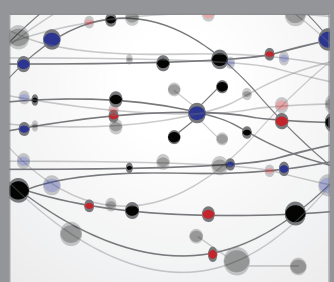

The Scientific World Journal
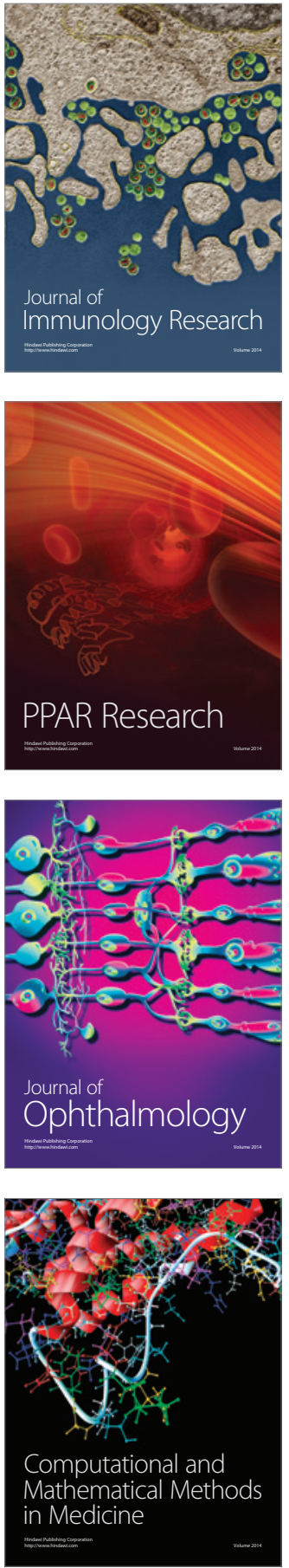

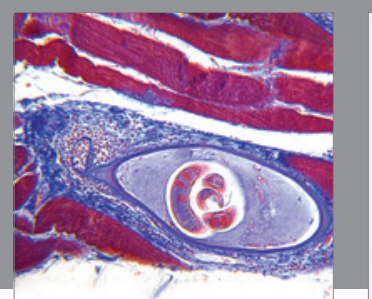

Gastroenterology Research and Practice

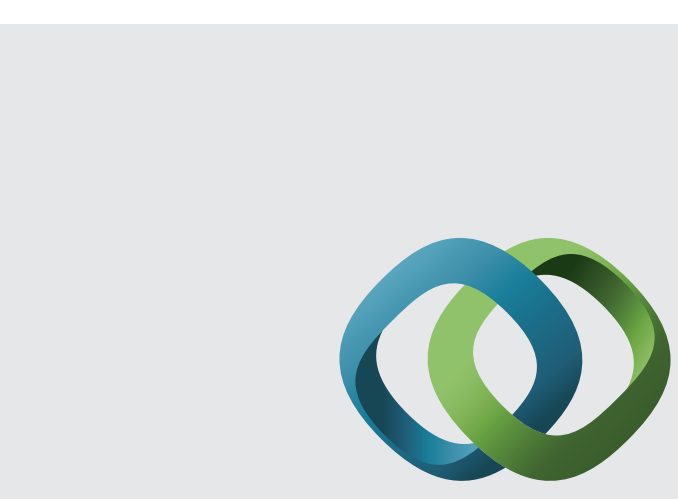

\section{Hindawi}

Submit your manuscripts at

http://www.hindawi.com
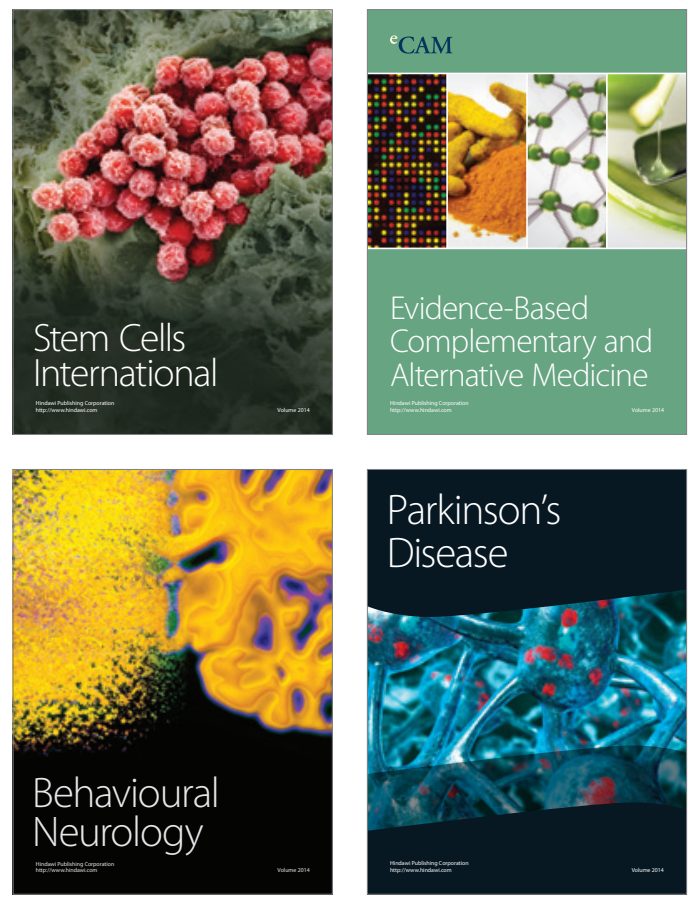
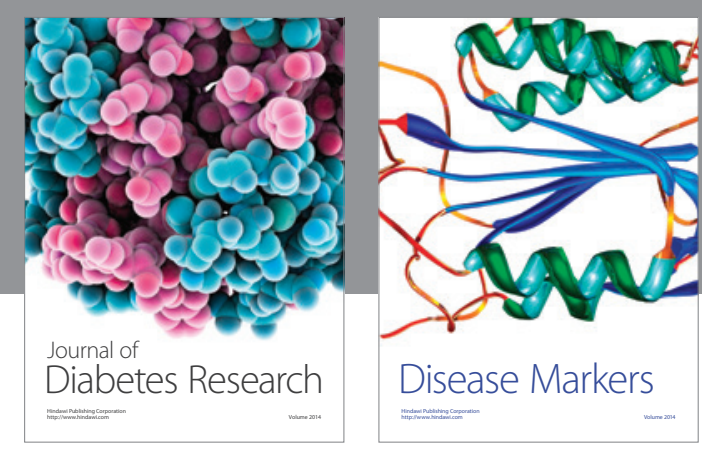

Disease Markers
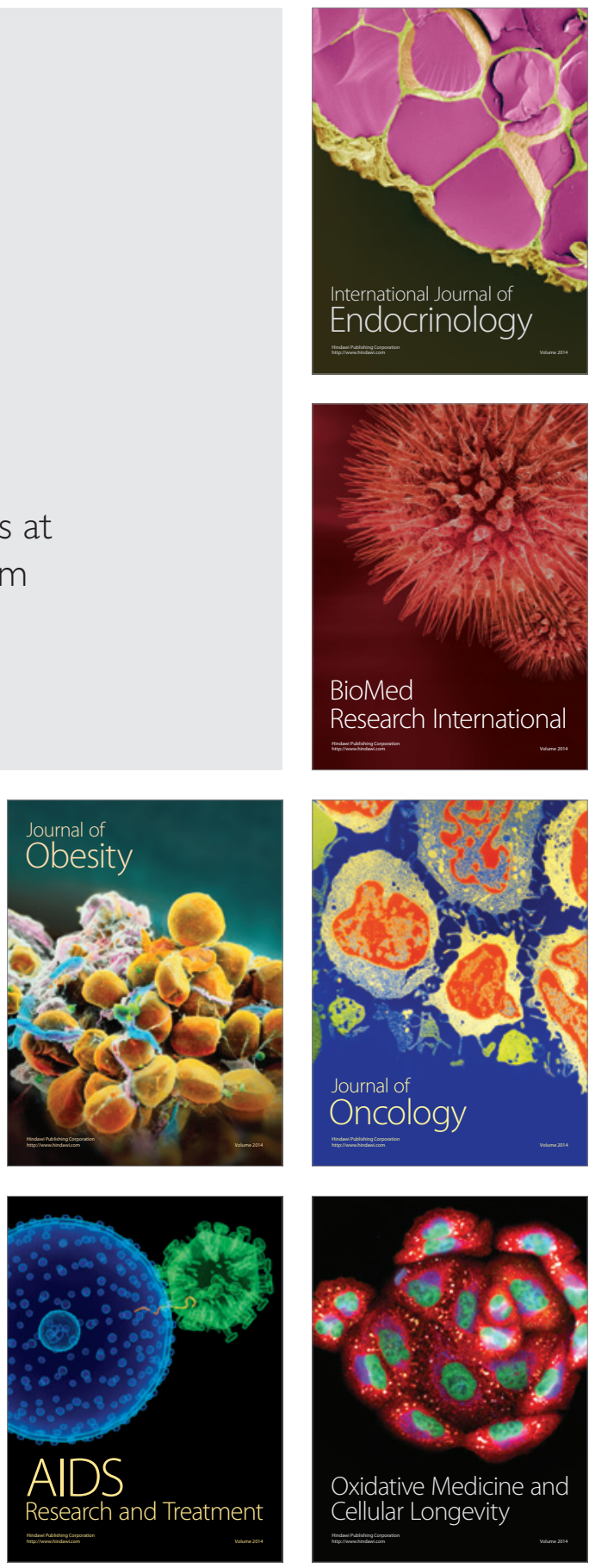